\title{
AS EPISTEMOLOGIAS DA DOCÊNCIA EM GEOGRAFIA: POR ENTRE CONCEPÇÕES E PRÁTICAS DE ENSINO
}

The epistemologies of teaching in Geography: between conceptions and didatic practices

\author{
Victória Sabbado Menezes* \\ Nestor André Kaercher ** \\ *Doutoranda do PPG em Geografia da UFRGS - victoriasabbado@gmail.com \\ ** Docente do PPG em Geografia da UFRGS - nestorandrek@gmail.com
}

Recebido em 04/08/2018. Aceito para publicação em 20/08/2018.

Versão online publicada em 03/09/2018 (http://seer.ufrgs.br/paraonde)

\begin{abstract}
Resumo:
A pesquisa relaciona-se à temática da "Educação geográfica e formação de professores" e tem como objetivo conhecer as concepções epistemológicas de Geografia e de Educação que assentam as práticas educativas de professores e acadêmicos de Geografia do município de Pelotas/RS. O caminho metodológico é constituído pela revisão bibliográfica, pesquisa documental e pesquisa de campo. Adotou-se a técnica da observação simples e da entrevista por pautas e o método de análise do conteúdo. A pesquisa revelou um pluralismo epistemológico tanto nas concepções teóricas quanto na ação pedagógica, de modo que não há uma única corrente da Geografia e da Educação sobre a qual os sujeitos se apoiam. Observou-se também uma discrepância entre a epistemologia da prática de professores e acadêmicos, o que evidencia a necessidade de repensar nossas concepções a partir do estudo e diálogo constante entre os educadores, sejam eles iniciantes ou experimentados.
\end{abstract}

Palavras-chave: Educação geográfica; concepções epistemológicas; formação docente.

\begin{abstract}
:
The present research is related to the theme "Geographical education and teacher training", and it aims at knowing the epistemological conceptions of Geography and Education that are based on the educational practices of Geography teachers and academics in the municipality of Pelotas, RS. The methodological path is constituted by bibliographic review, documentary research, and field research. It was adopted the technique of simple observation and interview by guidelines and the method of content analysis. The research revealed some epistemological pluralism in both the theoretical conceptions and the pedagogical action, so that there is not a single Geography and Education current about which the subjects are supported. It was also observed some variance between the epistemology of the practice of teachers and academics, which shows that it is necessary to rethink our conceptions from the study and to have constant dialogue between educators, either beginners or experienced.
\end{abstract}

Key-words: Geographical education; Epistemological conceptions; Teacher training.

\section{Introdução}

O presente artigo foi apresentado no XII Encontro Nacional da Associação Nacional de PósGraduação em Geografia e selecionado como número especial do referido evento para ser publicado nesta Revista. 0 trabalho visa apresentar os resultados de uma dissertação de mestrado defendida em 2016 no Programa de Pós-Graduação em Geografia da UFRGS (Universidade Federal do Rio 
Grande do Sul) referente à linha de pesquisa em Ensino de Geografia. O problema de pesquisa consiste no seguinte questionamento: quais as concepções epistemológicas de Geografia e de Educação que assentam as práticas educativas de professores e acadêmicos de Geografia? Pressupõese que toda prática do professor provém das concepções que apresenta, isto é, de determinadas linhas teóricas da Educação e da Geografia, embora muitas vezes o mesmo não tenha consciência disso. Ao constatar deficiências no ensino de Geografia, salienta-se a necessidade de pensar as concepções teóricas que sustentam o fazer pedagógico dos educadores.

Os eixos basilares desta pesquisa são: Ensino de Geografia e Formação de professores. Sendo assim, os sujeitos pesquisados constituem dois grupos distintos: 5 professores de Geografia de escolas estaduais de Pelotas/RS e 5 licenciandos em Geografia da Universidade Federal de Pelotas (UFPel). 0 caminho metodológico é formado por três momentos: revisão bibliográfica, pesquisa documental e pesquisa de campo (observações das aulas dos sujeitos e entrevista por pautas). Para o tratamento dos dados levantados nas entrevistas adotou-se o método de análise do conteúdo.

Logo, esta pesquisa busca pensar o ensino de Geografia a partir da realidade escolar. Parte-se do princípio que não é possível elaborar considerações sobre a Geografia escolar sem o diálogo com aqueles que a constroem diariamente nas instituições escolares. Da mesma forma, repensar a formação inicial docente exige a escuta dos acadêmicos, futuros professores. Desse modo, não se pretende apresentar fórmulas mágicas para a Educação e para o ensino de Geografia, mas sim provocar questionamentos e reflexões de cunho epistemológico sobre a prática docente. Assim, propõe-se com este trabalho navegar na "nau da loucura no mar das ideias" (VITOR RAMIL, 1987), visto que o debate de ideias possibilita repensar nossas práticas sociais, as epistemologias da docência em Geografia e o modo de ver e estar no mundo.

\section{As concepções teóricas e a epistemologia da prática do/a professor/a de Geografia}

A principal constatação decorrente da pesquisa de campo corresponde à existência de pluralismo e contradição epistemológica, percebida tanto no fazer pedagógico quanto nas concepções teóricas dos sujeitos pesquisados. Notou-se que principalmente as práticas pedagógicas não são orientadas por uma única vertente da Geografia e da Educação. Desse modo, não é possível classificar um professor como representante de um determinado modelo epistemológico e/ou pedagógico. A prática docente é muito mais que somente empirista ou apriorista ou construtivista, assim como a Geografia trabalhada muitas vezes não é exclusivamente Tradicional ou Quantitativa ou Crítica ou Humanista ou Cultural. Não é só, mas é também. Não é isso ou aquilo, mas é isso $e$ aquilo. Logo, a prática pedagógica é composta de elementos provenientes de distintas correntes de pensamento, ainda que estas aparentem ser antagônicas.

Já as concepções teóricas dos acadêmicos e professores eram mais lineares. Nos seus discursos percebeu-se que uma determinada linha teórica da ciência geográfica se sobressaía frente às demais. Cabe destacar que a concepção de Geografia era mais fácil de identificar através da fala dos sujeitos nas entrevistas do que na observação de suas práticas. Isso porque o seu fazer pedagógico caracterizava-se por múltiplas vertentes da Geografia, evidenciando um pluralismo epistemológico. Embora suas concepções de Geografia estivessem mais nítidas por meio da análise do conteúdo das entrevistas, isso não significa, necessariamente, a clareza dos mesmos quanto aos pressupostos epistemológicos que fundamentam sua visão de Geografia e seu ensino. Muitos demonstraram em suas respostas um entendimento confuso acerca do objeto, objetivos e finalidades da ciência geográfica e do ensino deste componente curricular na escola básica.

Entre as correntes do pensamento geográfico presentes nas concepções teóricas dos sujeitos pesquisados estão: a Geografia Tradicional, a Geografia Crítica e a Geografia Humanista. A corrente tradicional foi identificada nas entrevistas a partir da ideia de Geografia como ciência de síntese e/ou como descrição da Terra, sendo esta última considerada por Moraes (1997, p. 13) como "a mais usual, e ao mesmo tempo a de maior vaguidade". Essa perspectiva foi predominante no grupo de 
professores, mas também esteve presente nas afirmações de alguns acadêmicos. A corrente crítica que, para Moreira (1982, p. 14) "serve para desvendar máscaras sociais", está relacionada aos argumentos apresentados de que a Geografia amplia a visão de mundo, permite uma reflexão sobre o espaço para entender as relações sociais e possibilita a formação de um cidadão crítico e atuante na sociedade. Essa concepção teórica de Geografia Crítica estava explícita nas falas de dois acadêmicos e de uma professora.

A corrente humanista foi reconhecida nas considerações que defendiam uma Geografia ligada à vida dos alunos, às suas vivências e ao cotidiano. Isso porque tal corrente valoriza o conceito de lugar através da ideia do vivido e experienciado, "privilegiando o singular e não o particular ou o universal" (CORRÊA, 2012, p. 30). Deve-se ressaltar que foi mais comum encontrar concepções pautadas pela articulação entre Geografia Tradicional e Humanista ou entre Geografia Crítica e Humanista do que entre Geografia Tradicional e Crítica.

No que concerne à comparação entre os grupos de sujeitos, constatou-se que as concepções teóricas de Geografia dos acadêmicos são, em geral, orientadas por uma linha "mais crítica" do que as manifestadas pelos professores. Contudo, essa crítica não significa, necessariamente, que ponderam diferentes linhas de raciocínio. Chamou a atenção o fato de ambos os grupos apresentarem uma visão de certa forma confusa da Geografia, especialmente ao não salientar seu objeto de estudo. Do total de dez sujeitos, apenas quatro (três professores e um acadêmico) fizeram referência em algum momento da entrevista à Geografia como estudo do espaço geográfico. Isso preocupa, pois evidencia uma certa displicência com a raiz epistêmica da Geografia. Diante disso, a que fatores pode-se atribuir esta questão? Por que a falta de clareza sobre a definição de Geografia é mais presente entre acadêmicos do que professores? Que implicações isso pode acarretar nas práticas de ensino de Geografia na escola? Seria a formação inicial uma das responsáveis por tal carência nas concepções teórico-epistemológicas destes sujeitos?

Considera-se que para ensinar Geografia é fundamental que o educador esteja ciente do que se trata e para que serve a ciência com a qual dedica seu trabalho docente a fim de que evite o desenvolvimento de um ensino de Geografia como o que Kaercher (2007) denomina de "Gigante de pés de barro", isto é, uma epistemologia pobre e uma pedagogia confusa por parte do professor. Defende-se que para movimentar-se com o mínimo de segurança em suas práticas é necessário apoiar-se em uma teoria, o que corresponde às suas concepções epistemológicas. Pressupõe-se que a formação inicial deve fornecer os subsídios para garantir uma fundamentação teóricoepistemológica consistente aos futuros professores. Contudo, é intrigante que mesmo com esta fragilidade epistemológica observada, os próprios sujeitos afirmaram que a licenciatura lhes proporcionou uma base teórica sólida, principalmente no que se refere à ciência geográfica. Suas críticas direcionavam-se apenas à formação pedagógica.

Na relação entre concepção teórica de Geografia e epistemologia da prática, a literatura acadêmica reitera que, na maioria das vezes, as concepções teóricas são mais progressistas que as práticas educativas. Verificou-se esta realidade ao analisar o confronto entre teoria e prática dos acadêmicos, porém o mesmo não ocorreu com os professores. Deste grupo, somente dois desenvolveram em ensino de Geografia mais conservador e tradicional do que seu discurso. Já outras três professoras apresentaram em seu fazer docente uma visão mais crítica de Geografia do que suas afirmações teóricas concedidas na entrevista. Este fato chamou a atenção e pode estar associado aos anos de experiência das professoras que, embora tenham um discurso mais conservador, desenvolveram uma sensibilidade para escutar e dialogar com os alunos, aproximando-se do conceito de "educadoras" em vez de restringirem-se ao papel de "transmissoras" de conteúdo.

Outro ponto que deve ser destacado refere-se à constatação de que o sujeito que apresenta uma concepção epistemológica de Geografia caracterizada predominantemente pela perspectiva crítica radical, por exemplo, não possui, necessariamente, uma concepção epistemológica de Educação Crítica e/ou construtivista. Isso também se aplica à prática, ou seja, desenvolver um ensino de Geografia Crítica e/ou Humanista não elimina a possibilidade de praticar uma Educação assentada na epistemologia empirista. As práticas de uma professora representam um exemplo, pois apresentava 
uma visão crítica da Geografia e desenvolvia um ensino empirista com atividades mecânicas e pautadas no reprodutivismo. Sendo assim, é importante enfatizar a complexidade na atividade do ensinar, uma vez que a contradição é inerente aos fazeres da docência.

Tanto os professores quanto os acadêmicos apresentam, em geral, uma visão conteudista de Geografia em sua ação docente. Teve-se dificuldade em perceber a(s) perspectiva(s) da ciência geográfica que embasavam suas práticas, tendo em vista o enfoque que concediam aos conteúdos curriculares. Na grande maioria das vezes, os conteúdos geográficos eram concebidos como fim do processo educativo.

Ao agir assim, direcionamos o foco do trabalho ao produto - o conteúdo - e abandonamos o compromisso fundante da docência: possibilitar que o aluno aprenda e seja capaz de mobilizar suas aprendizagens em diferentes situações. Ao apostar na transmissão de conteúdos de Geografia, relegamos a um segundo plano o que é essencial, a possibilidade de agir na direção do conhecimento, na formação de competência e atitudes com base nas quais os alunos se situem na complexidade do mundo com autonomia e identidade. (COSTELLA; SCHAFFER, 2012, p. 42)

Percebeu-se que o grupo de acadêmicos era mais preocupado em abordar e, nas palavras de alguns destes sujeitos, transmitir os conteúdos geográficos aos alunos do que o grupo de professores. Este último, embora atentasse para o tratamento dos conteúdos, preocupava-se claramente com a formação humana, isto é, com a formação integral dos educandos. Essa questão foi observada em suas práticas, mas também ratificada por alguns destes professores nas entrevistas.

No que diz respeito às concepções teórico-epistemológicas de Educação, as ideias defendidas pelos sujeitos compreendem as vertentes do empirismo e do construtivismo. Cabe ressaltar que a epistemologia apriorista não esteve presente nas falas dos entrevistados nem nas práticas de ensino de nenhum deles. As concepções teóricas dos professores, com exceção de uma professora que defendeu o construtivismo, estão diretamente associadas à linha empirista. Conforme esta corrente, "permanece inalterado o fato de que o conhecimento provém do exterior, do mundo dos estímulos/ o conhecimento é 'a apreensão de uma verdade', e não sua construção" (BECKER, 1993, p. 41). Como se percebeu na pesquisa de campo, a maioria dos professores entende o ensino como uma prática de transferência ou transmissão de conteúdo. Sendo assim, não houve um descompasso entre as concepções de Educação e as práticas educativas dos professores, pois ambas caracterizam-se pela epistemologia empirista.

Por sua vez, os acadêmicos apresentaram concepções referentes à epistemologia construtivista ao enfatizarem a importância do diálogo e defenderem a perspectiva de professor mediador, exceto um acadêmico que considera o ensino como transmissão de conhecimento. A fala dos acadêmicos se aproximava da corrente construtivista ao considerar que "o conhecimento se dá por um processo de interação radical entre sujeito e objeto, entre indivíduo e sociedade, entre organismo e meio" (BECKER, 2001, p. 36). Torna-se evidente a distinção das concepções teóricas de Educação entre o grupo de professores e o de acadêmicos. 0 primeiro defende perspectivas mais tradicionais e conservadoras que o segundo. No entanto, é digno de nota que as práticas pedagógicas dos acadêmicos não se caracterizaram por ser tão construtivistas como os mesmos afirmaram nas entrevistas. Conforme observado em suas aulas de estágio, as práticas possuíam um caráter predominantemente empirista com nuances de uma epistemologia construtivista.

Deve-se assinalar que a visão que os acadêmicos têm sobre ensino e Educação é mais clara para os mesmos do que sua concepção de Geografia. Percebeu-se nas entrevistas que estes sujeitos estão conscientes do tipo de ensino que pretendem desenvolver, a postura que querem assumir enquanto professor e as estratégias metodológicas que buscam adotar. Contudo, o mesmo não ocorre em relação à sua visão de Geografia, pois não demonstraram em suas falas uma clareza quanto à definição de Geografia e sua finalidade em sala de aula. Assim, pode-se afirmar que as concepções teóricas de Geografia dos acadêmicos são mais confusas e menos fundamentadas que suas 
concepções de Educação.

Entre o grupo de professores esta nítida discrepância não foi observada. Diante disso, supõe-se que a abordagem epistemológica da Educação foi melhor trabalhada ao longo do curso de formação dos acadêmicos do que as questões relacionadas à epistemologia da Geografia. Como a licenciatura pode fortalecer a discussão epistemológica da Geografia? Em paralelo, cabe aos acadêmicos buscarem, de forma autônoma, materiais complementares que lhes possibilitem um aprofundamento teórico que permita a (re)construção de concepções mais sólidas, uma vez que se o intuito é provocar mudanças no ensino, deve-se considerar que "não haverá transformação sem reforma do pensamento, ou seja, revolução nas estruturas do próprio pensamento." (MORIN, 2005, p. 10).

Observou-se nas aulas de acadêmicos e professores que, na maioria das vezes, as práticas construtivistas são pontuais. Principalmente os acadêmicos que apresentaram concepções de um ensino mais crítico e construtivista não conseguiram desenvolver comumente uma ação pedagógica condizente com seu discurso. Considera-se que ainda há uma hegemonia do empirismo em sala de aula, mesmo quando o sujeito defende ideias contrárias a esta perspectiva, acarretando em uma contradição entre teoria e prática. Isso ratifica o que Becker (1993) preconiza, pois ainda que os sujeitos se aproximem de outras posturas,

não conseguem superar totalmente sua epistemologia empirista. Numa palavra, todos os docentes são, pelo menos em algum grau, empiristas. Ela é, também, a postura mais claramente verbalizada; talvez por ser a que mais se aproxima do senso comum. Ou seja, é aquela que é professada aquém de qualquer questionamento. (BECKER, 1993, p. 39)

E por que isso acontece? Atribui-se esta questão à naturalização do empirismo. Isto é, ainda que ao longo da licenciatura o sujeito construa noções de uma Educação Crítica e passe a defender um ensino dialógico e pautado na construção do conhecimento, isso não garante que desenvolverá práticas educativas de acordo com esta linha de pensamento, uma vez que a formação inicial constitui apenas uma das fontes dos conhecimentos docentes (TARDIF, 2014). A história de vida escolar e as vivências como aluno geralmente são marcadas pela presença da epistemologia empirista. Assim, as experiências empiristas na condição de aluno são, geralmente, muito mais frequentes que as experiências construtivistas. Logo, superar o modelo de formação da educação básica representa um desafio.

Por consequência, provocar esta desnaturalização do empirismo refere-se a um processo longo a ser realizado pelo sujeito educador. A clareza das concepções de Educação e de Geografia, bem como dos objetivos que se visa alcançar no ensino são necessários, porém insuficientes. É essencial que as concepções teóricas estejam articuladas à epistemologia da prática docente. Isso pressupõe superar a visão dicotômica entre teoria e prática. Desse modo, a prática não se restringe à aplicação da teoria. Pelo contrário, tanto a teoria quanto a prática produzem saber e são complementares. Nesse sentido, a formação inicial deve ser repensada a fim de formar um professor pesquisador e reflexivo, pois "a pesquisa maior dos mestres não deverá ser somente dos amparos técnicos da sua ciência, a pesquisa deverá pautar no aluno, no reconhecimento do pensar do aluno, só assim as dificuldades e os caminhos da aprendizagem serão entendidos" (COSTELLA, 2011, p. 3).

Uma reforma na formação universitária com o aumento de carga horária nos currículos para a realização de experiências práticas, conforme reivindicaram nas entrevistas, é importante. Todavia, não basta apenas ter um número maior de vivências de práticas de ensino durante a licenciatura; é fundamental que estas sejam acompanhas de uma reflexão epistemológica e pedagógica. Isso requer uma formação que considere os professores do ensino básico como sujeitos do conhecimento para que contribuam com seus saberes profissionais na formação de futuros educadores. As entrevistas demonstraram por meio da diversidade de respostas dos sujeitos que não há um único caminho para ser um bom professor. Trata-se de um conjunto de fatores, o que requer essa troca permanente entre professores e futuros professores. 
Outro ponto salientado pelos sujeitos pesquisados foi o fato de que a formação inicial, apesar de apresentar aspectos positivos, não os prepara para ensinar, além de tratar de uma realidade muito distante daquela que compreende o espaço escolar. É interessante que grande parcela destes concluiu a partir de sua prática docente que não há fórmulas para ensinar, mas ao mesmo tempo esperam que a licenciatura os apresente estas receitas. Sendo assim, revela-se a complexidade da profissão docente e reitera-se a necessidade premente de que as licenciaturas busquem formar professores pesquisadores e reflexivos. Ou seja, "a formação deve estimular uma perspectiva críticoreflexiva, que forneça aos professores os meios de um pensamento autônomo e que facilite as dinâmicas de autoformação participada" (NÓVOA, 1995, p. 25).

Depreende-se que a docência não pode ser uma atividade solitária. Por isso, considera-se extremamente profícuo o diálogo e a troca entre professores, sejam eles da mesma área ou de áreas diferentes, pois o objetivo deve consistir em, a partir do contato com o outro, contribuir com o mesmo e refletir sobre seu fazer docente. Este exercício também deve ser inserido na formação universitária através da relação dialógica entre acadêmicos, professores universitários e professores de escolas, o que possibilitará uma aproximação entre universidade e escola.

No que se refere às práticas pedagógicas, deve-se destacar que o predomínio do empirismo não resultou na prática exclusiva de uma pedagogia diretiva. Os fazeres pedagógicos dos acadêmicos e professores não incluiu a pedagogia não-diretiva, mas caracterizavam-se por elementos da pedagogia diretiva e relacional. Observou-se uma boa relaç]ao entre os sujeitos da aprendizagem. Entretanto, esta não era direcionada para efetivar uma interação mais intensamente cognitiva e a troca de conhecimento. Chamou a atenção que o diálogo dificilmente era estabelecido em sala de aula. Embora não houvesse uma relação autoritária e/ou coercitiva do professor sobre os alunos, percebeu-se muitas vezes certo conformismo de ambas as partes. Notou-se o que Kaercher (2014) denomina de "disciplina burocrática", na qual não há desacomodação do pensamento dos alunos. Diante disso, o autor enfatiza a relevância de provocar uma tensão cognitiva, visto que "ao tensionar movimentamos o pensar, nosso e de nossos alunos. Temer o conflito pode renegar a escola ao marasmo." (KAERCHER, 2014, p. 97).

O trabalho de campo demonstrou que a curiosidade e a dúvida existem sim na mente dos alunos. Esses elementos tão essenciais para o desenvolvimento de um processo de aprendizagem significativo aos educandos não foram eliminados, mesmo com uma tradição escolar que pouca estimula a formulação de perguntas. Torna-se necessário resgatá-los, de maneira que sejam oferecidas as condições que encorajem a expressão dos alunos quanto aos seus interesses, questionamentos e incertezas. No entanto, em raras ocasiões os educandos foram estimulados a sair de sua zona de conforto, o que impedia a instauração de uma tensão cognitiva. 0 conteúdo era apresentado à turma sem ser problematizado, mas como algo pronto e acabado. Assim, sem a problematização não se desencadeava o confronto de pontos de vista e, consequentemente, as aulas transcorriam com pouca reflexividade. Eis aqui uma questão preocupante: preza-se o conteúdo e esquece-se da reflexão. Como desenvolver uma aprendizagem significativa sem reflexão?

\section{Considerações Finais}

Ao longo do trabalho, salientaram-se alguns achados e pontos positivos, como concepções epistemológicas que representam o desejo de desenvolver um ensino crítico de Geografia, práticas pedagógicas caracterizadas por uma relação amigável entre professores-aluno e abordagens geográficas relacionadas ao contexto local e à vida dos educandos. Desse modo, assim como se constatou algumas questões de natureza epistemológica que devem ser repensadas e alguns desafios para a formação do professor, também foram indicados caminhos, através de contribuições dos sujeitos da pesquisa, que podem ser experimentados na docência.

Assinala-se que a partir das considerações aqui explicitadas tenha sido possível refletir sobre o quadro atual do ensino de Geografia e pensar como a formação inicial pode auxiliar no processo de 
formação de educadores que estejam seguros com suas práticas e tenham clareza no que diz respeito aos pressupostos que as fundamentam. Discutir a epistemologia do trabalho docente é fundamental para que os educadores atentem para os pilares que sustentam seu fazer pedagógico e possam desenvolver práticas significativas aos educandos, visto que uma mudança meramente metodológica não é suficiente. É necessária uma mudança epistemológica.

Buscou-se alcançar as raízes do fazer docente a fim de propiciar reflexões acerca da epistemologia do professor de Geografia, pois considera-se que mudanças nas práticas de ensino estão atreladas às mudanças do pensamento. Contudo, esse desejo de transformação somente é possível se for alimentado pela utopia. Sendo assim, reivindica-se: por mais utopia e inconformismo no ensino de Geografia, tendo em vista que "somos o que fazemos, e sobretudo o que fazemos para mudar o que somos: nossa identidade reside na ação e na luta. Por isso a revelação do que somos implica na denúncia do que nos impede de ser o que podemos ser" (GALEANO, 1999, p. 15). Cabe a nós atentarmos para as amarras que pretendem imobilizar nossos movimentos docentes, assumirmos nosso inacabamento e atuarmos com coerência aos princípios que defendemos. Sejamos, então, mais autônomos e ousados na nossa maneira de estar no mundo para que se possa ser o que se quer ser.

\section{Referências}

BECKER, Fernando. A epistemologia do professor: o cotidiano da escola. 10. Ed. Petrópolis, RJ: Vozes, 1993.

BECKER, Fernando. Educação e construção do conhecimento. Porto Alegre: Artmed, 2001.

CORRÊA, Roberto Lobato. Espaço, um conceito-chave da Geografia. In: CASTRO, Iná Elias de.; GOMES, Paulo Cesar da Costa.; CORRÊA, Roberto Lobato (Orgs.). Geografia: conceitos e temas. Rio de Janeiro: Bertrand Brasil, 2012. (p. 15-47).

COSTELLA, Roselane Zordan. Competências e habilidades no contexto da sala de aula - ensaiando diálogos com a teoria piagetiana. Cadernos do Aplicação, Porto Alegre, v. 24, n. 1, jan./jun. 2011.

COSTELLA, Roselane Zordan; SCHAFFER, Neiva Otero. A Geografia em projetos curriculares: ler o lugar e compreender o mundo. Erechim: Edelbra, 2012.

GALEANO, Eduardo. A descoberta da América (que ainda não houve). Porto Alegre: EdUFRGS, 1999.

KAERCHER, Nestor André. A Geografia escolar: gigantes de pés de barro comendo pastel de vento num fast food. Terra Livre, Presidente Prudente, v. 1 n² 28, p. 28-44, Jan-Jun. 2007.

KAERCHER, Nestor André. Se a geografia escolar é um pastel de vento o gato come a geografia crítica. Porto Alegre: Evangraf, 2014.

MORAES, Antonio Carlos Robert. Geografia: pequena história critica. São Paulo: Hucitec, 1997.

MOREIRA, Ruy (Org.) A Geografia serve para desvendar máscaras sociais. In: Geografia: teoria e critica; o saber posto em questão. Petrópolis: Vozes, 1982.

MORIN, Edgar. Ciência com consciência. Rio de Janeiro: Bertrand Brasil, 2005.

NÓVOA, Antonio. Formação de professores e profissão docente. In: NÓVOA, António (coord). Os professores e a sua formação. 2 ed. Lisboa: Instituto de Inovação Educacional, 1995. (p. 13-33).

TARDIF, Maurice. Saberes docentes e formação profissional. 16. ed. Petrópolis: Vozes, 2014.

VITOR RAMIL. Joquim. In: VITOR RAMIL. Tango. Rio de Janeiro: EMI, 1987. 1 CD. Faixa 4. 